\title{
Effectiveness of Endovascular Coil Embolization of Ruptured Hepatic Artery Pseudoaneurysm
}

\author{
Jung Wook Seo \\ Department of Radiology, Ilsan Paik Hospital, Inje University College of Medicine, Goyang-si, Korea \\ Email: seojwrad@paik.ac.kr
}

How to cite this paper: Seo, J.W. (2017) Effectiveness of Endovascular Coil Embolization of Ruptured Hepatic Artery Pseudoaneurysm. Advances in Computed Tomography, 6, 7-15.

https://doi.org/10.4236/act.2017.62002

Received: May 15, 2017

Accepted: June 27, 2017

Published: June 30, 2017

Copyright $\odot 2017$ by author and Scientific Research Publishing Inc. This work is licensed under the Creative Commons Attribution International License (CC BY 4.0).

http://creativecommons.org/licenses/by/4.0/

\begin{abstract}
Purpose: To assess the efficacy of endovascular management for ruptured hepatic artery pseudoaneurysm (HAP). Methods: Six cases of HAP in five patients (four men and one women; mean age, 50; range, 28 - 62) were treated with transcatheter arterial coil embolization using microcoil (Boston Scientific, Watertown, MA, USA) and Tornado Coil (Cook, Bloomington, IN, USA) with or without stent graft between January 2007 and September 2008. They were analyzed with regard to the clinical presentation, radiological findings with procedure, and clinical and radiologic outcomes. Results: All patients presented with epigastric pain or gastrointestinal bleeding. The pseudoaneurysms were ranged from 0.6 to $4.4 \mathrm{~cm}$ in size and located in the common hepatic artery $(n=1)$, junction between proper and right hepatic artery $(n=1)$, proper hepatic artery $(n=2)$, the left hepatic artery $(n=1)$, right hepatic artery $(n=1)$. Embolization was performed with microcoils in all pseudoaneurysmal sac with or without both afferent and efferent segment. A self-expandable stent $(\mathrm{n}=1)$ was also used. Overall technical success was $100 \%$ (6 of 6$)$ and complete occlusions of HAPs were achieved in 5 out of 6 cases, $83.3 \%$ of clinical success rate. Re-bleeding occurred in one case of stent graft at proper hepatic artery following coil packing for pseudoaneurysmal sac. Clinical success rate of embolization for both afferent and efferent segment was 100\% (3 of 3). Procedure-related minor complications happened in 2 of 5 patients, and they were treated conservatively. Conclusion: Transcatheter coil embolization for ruptured HAP is sufficiently effective and additional embolization in both afferent segment and efferent segment can improve clinical success rate.
\end{abstract}

\section{Keywords}

Hepatic Artery, Pseudoaneurysm, Rupture, Embolization, Endovascular 


\section{Introduction}

Hepatic artery aneurysms are rare but represent approximately 20\% of all visceral artery aneurysms [1] [2] [3]. Unlike true aneurysm, hepatic artery pseudoaneurysm (HAP) is caused by not only inflammation but also injurious causes such as surgery, trauma and percutaneous procedures [3]. Therefore, incidence of HAP is growing due to increase in laparoscopic or percutaneous hepatobiliary procedures and frequent use of computed tomography (CT) scanning [3] [4] [5]. The incidence of rupture ranges from $14 \%$ to $80 \%$ and mortality rate of rupture is at least 20\% [2] [3] [5]. Although treatment of HAP includes open surgery and minimally invasive interventional treatment, surgical procedures are gradually replaced by diverse kinds of endovascular or percutaneous transabdominal techniques in many published literature [5] [6] [7]. Percutaneous transabdominal techniques include direct injection of thrombin or glue and endovascular management include transcatheter arterial embolization or stent graft placement [5] [6]. Recent treatment of choice is endovascular arterial embolization and there are only a few reports trying for stenting [1] [5] [6]. However, most are case reports or limited large reviews of outcomes [6] [7]. Thus, we reviewed our experience of assessment of efficacy in endovascular managements for hepatic artery pseudoaneurysm.

\section{Materials and Methods}

\subsection{Patient Collection}

The approval of our institutional review board was obtained for a retrospective review of medical records including radiologic exams of five consecutive patients, who were diagnosed as ruptured HAP according to dynamic abdominopelvic CT that shows arterial hypervascular enhancing sac with ill defined, high attenuated hemorrhages, and treated with transcatheter arterial embolization with or without stent graft between January 2007 and September 2008.

There were five patients ( 4 men, 1 women; age 28 - 62 years, mean age 50 years) diagnosed as ruptured HAPs and one of 5 patients underwent the interventional procedure twice because of newly developed HAP in proper hepatic artery around resection margin. Therefore, 6 cases of endovascular treatments in 5 patients were analyzed about initial clinical and radiologic presentation, progress and final outcomes.

\subsection{Endovascular Interventional Procedures}

After diagnosis of ruptured HAP on dynamic abdominopelvic CT scans, angiography was performed. Selective angiography of celiac axis and superior mesenteric artery (SMA) was done to analyze the location, size, shaped of the HAP using a $5 \mathrm{~F}$ catheter.

For endovascular treatment of ruptured HAP, $5 \mathrm{~F}$ introducer sheath was exchanged in the right femoral artery and superselection of the vessels supplying the ruptured pseudoaneurysm was followed with a tip of 2.0 and $2.2 \mathrm{~F}$ microca- 
theter coaxially place through the $5 \mathrm{~F}$ catheter. Endovascular procedures were performed using microcoil (Boston Scientific, Watertown, MA, USA) and Tornado Coil (Cook, Bloomington, IN, USA) without $(\mathrm{n}=5)$ or with $(\mathrm{n}=1)$ self-expandable stent (Neuroform, Stryker, Kalamazoo, Michigan, USA).

Technical success was defined as complete exclusion of the pseudoaneurysm after the procedure, and a lack of active extravasation. Clinical success was defined as the cessation of active bleeding or no evidence of recurrent bleeding on follow-up CT, and lack of hepatic ischemia [8]. Clinical follow-up data were acquired by checking electronic medical records to detect whether there was recurrent bleeding.

\section{Results}

\subsection{Patients' Demographics and Initial Presentation}

The major initial presentation was upper gastrointestinal bleeding such as melena, hematemesis or anemia. Also upper abdominal pain was associated in 3 cases. Two patients had history of Whipple's operation but the others had no history of abdominal surgery. The detail description was shown in Table 1.

\subsection{Endovascular Interventional Management, Clinical Process and Outcome}

Selective angiography of celiac axis and superior mesenteric artery revealed six HAPs in each patient. Two of them were located at the proper hepatic artery in patients with history of Whipple's operation, the others were respectively located at common hepatic artery, at junction between proper hepatic and right hepatic artery, at right hepatic artery and at left hepatic artery. The largest dimension of them was ranged from 0.6 to $4.4 \mathrm{~mm}$ in long axis diameter.

Embolization was performed thorough placement of microcoils in aneurysmal sacs or both afferent and efferent segments in all 6 endovascular procedures of 5 patients. Additional self-expandable stent was placed in one procedure. The mean follow up period was 13 months (range, 5 - 24 months). After only coil embolization, hemostasis was achieved in 4 out of 5 patients without re-bleeding after follow up. In one patient, coil embolization of pseudoaneurysm sac was performed at junction between proper and right hepatic artery with placement

Table 1. Patients' demographics and clinical presentation.

\begin{tabular}{cccccc}
\hline Procedure Patient Sex Age & Initial presentation & Previous history \\
\hline 1 & 1 & F & 28 & Melena & Gastritis \\
2 & & & & Melena & Whipple's operation for CBD cancer \\
3 & 2 & M & 51 & $\begin{array}{c}\text { Hematemesis, epigastric pain, } \\
\text { hypotension }\end{array}$ & Resection of hepatic arterial aneurysm \\
4 & 3 & M & 60 & Anemia & Whipple's operation for CBD cancer \\
5 & 4 & F & 62 & Epigastric pain & Gastritis \\
6 & 5 & M & 52 & RUQ pain and fever & None \\
\hline
\end{tabular}


of self-expandable stent due to pre-existing hepatic ischemia. However, re-bleeding was noted in 5 day after procedures and the patient underwent surgical removal of coiled aneurysmal sac (Figure 1). After one-month follow up,

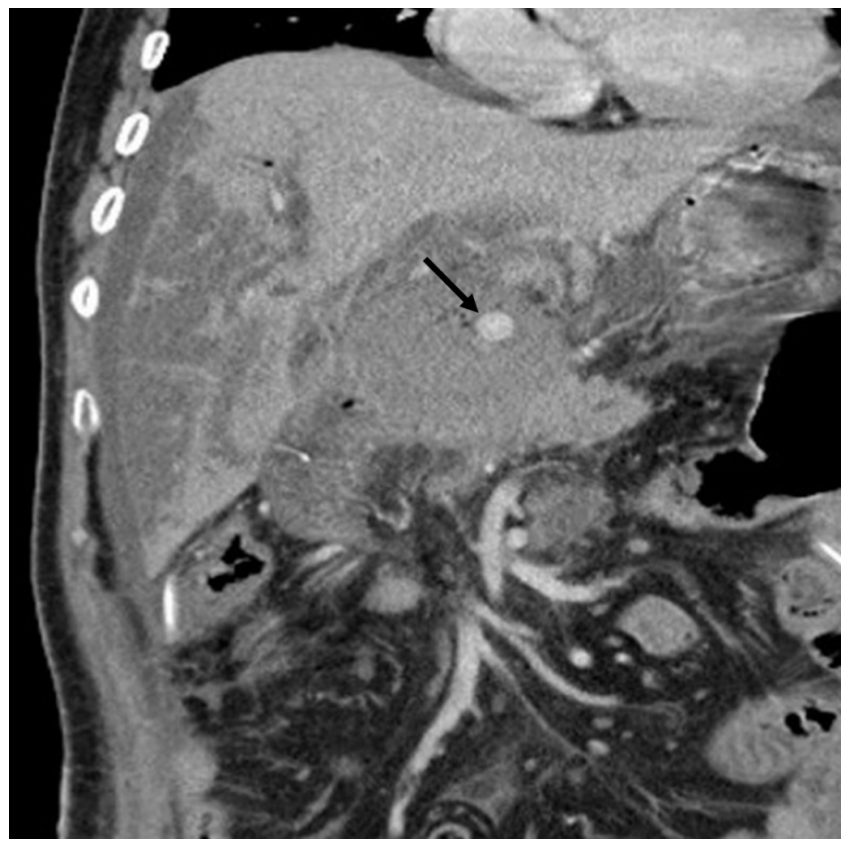

(a)

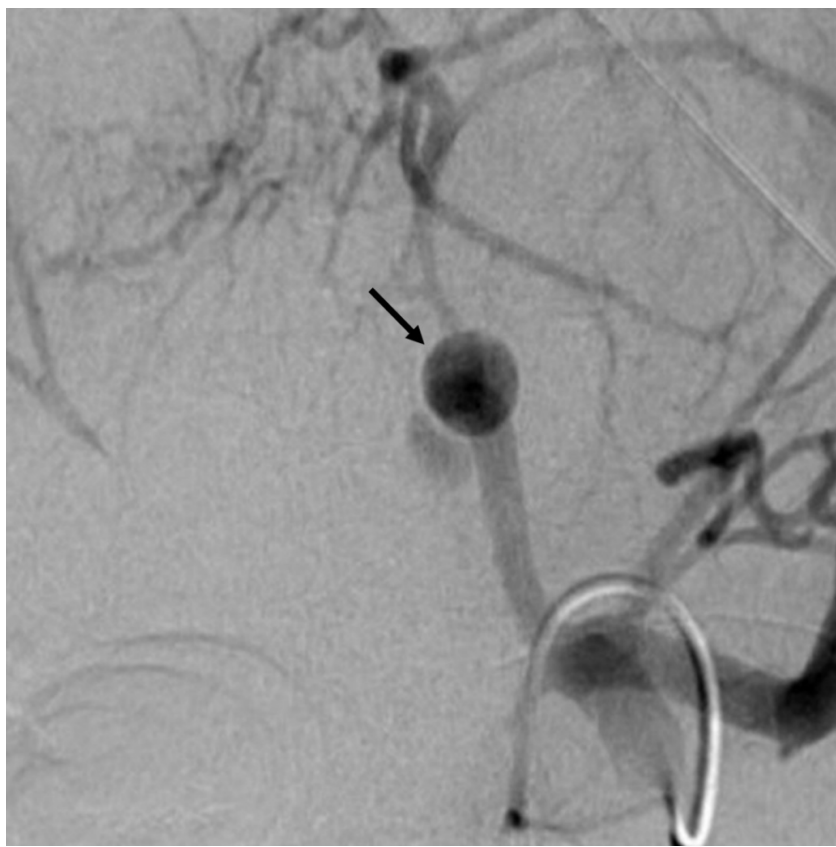

(c)

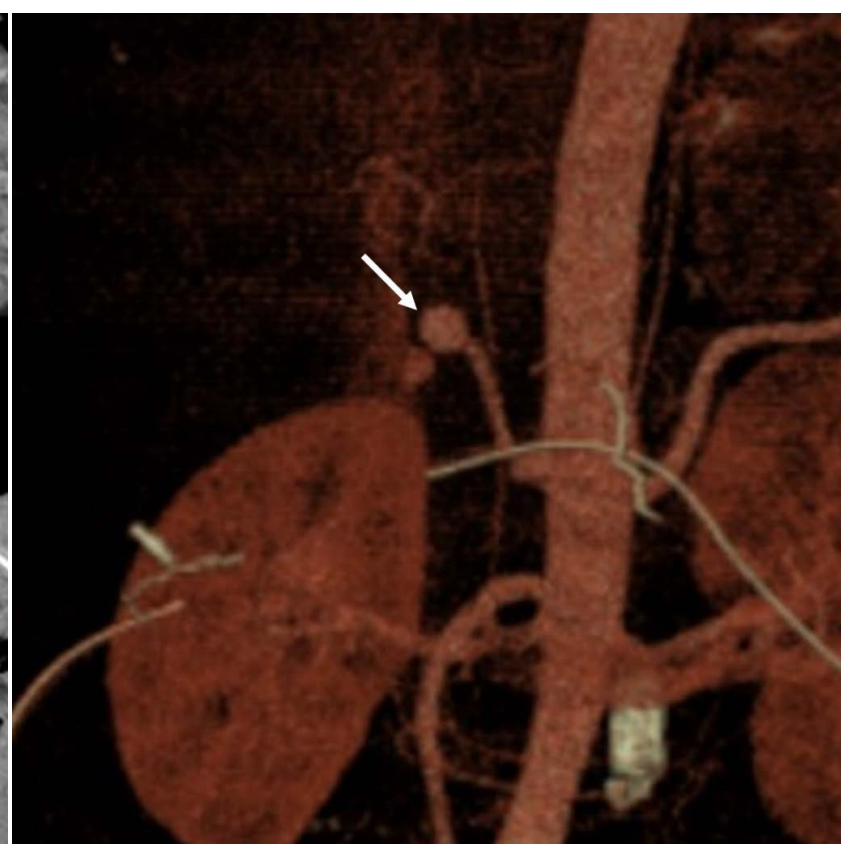

(b)

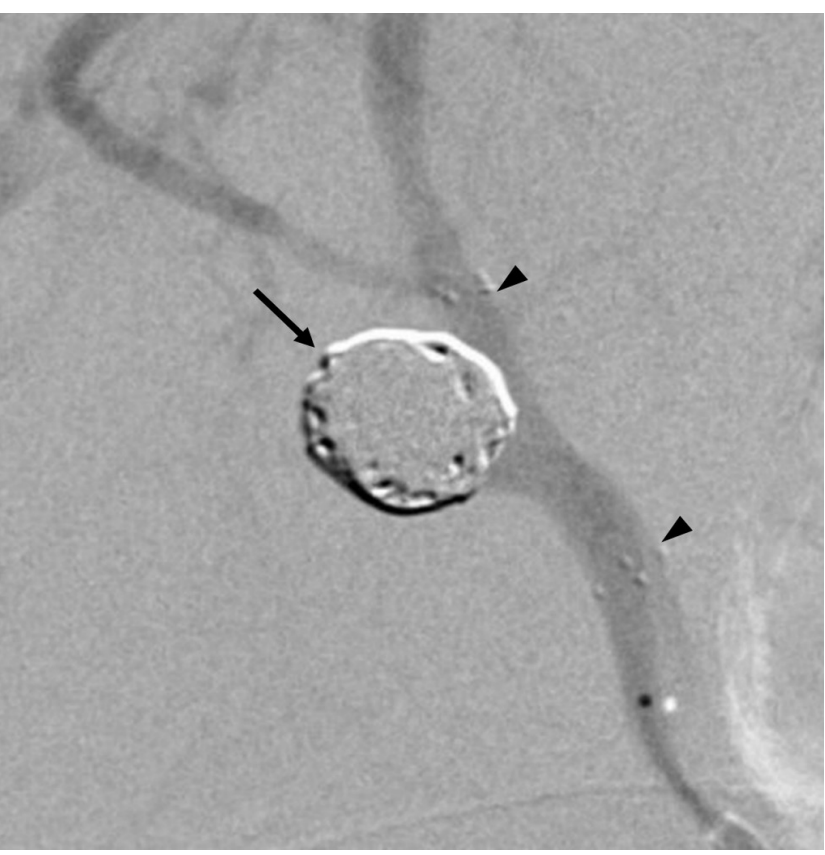

(d)

Figure 1. A 51-year old male with Whipple's operation for distal CBD cancer complaining melena and decreased hemoglobin. Abdominopelvic CT (a) and CT angiography (b) before procedure shows a $1.2 \times 1 \mathrm{~cm}$-sized pseudoaneurysm sac (arrow) in junction of proper hepatic artery to right hepatic artery. Hepatic arteriography shows pseudoaneurysm (arrow) in distal proper hepatic artery (c) and post embolization angiography shows coil packed pseudoaneurysm (microcoil, $9-5 \mathrm{~mm}$, $\times 9$ ) (arrow) with stent graft (Neuroform Stent, $4.5 \mathrm{~mm} / 20 \mathrm{~mm}$ ) (arrowheads) (d). In 5 days after procedures, re-bleeding was noted and the patient underwent surgical removal of coiled aneurysmal sac. 
another newly developed pseudoaneurysm was discovered at proper hepatic artery. He was treated with coil embolization but expired due to septic shock after 18 days after the second procedure. The detail procedural description was summarized in Table 2.

Immediate technical success was $100 \%$ (6 of 6 ) and complete occlusions of HAPs were achieved in 5 out of 6 cases, $83.3 \%$ of clinical success rate. Embolization of both afferent and efferent segment was performed in three procedures and there was no evidence of re-bleeding on follow up, $100 \%$ of clinical success rate (Figure 2). Re-bleeding occurred in one of three coil-packing aneurysms without additional embolization of afferent segment, $66 \%$ of clinical success rate. This re-bleeding case of HAP had been already ruptured before procedure, however immediate operation was not feasible due to large amount of hematoma on initial CT scans. Because the bleeding HAP was located at junction between proper hepatic artery and right hepatic artery resulting in global parenchymal ischemia, a $2 \mathrm{~cm}$-long stent graft was deployed along proper hepatic artery for preservation of right hepatic arterial supply then only bleeding HAP was packed by coils without additional embolization of arterial segments. Re-bleeding was developed from coil-packed aneurysm after 5 days and it was surgically removed. One month later surgical resection, another new pseudoaneurysm developed around resection margin at proper hepatic artery and treated by coil packing of only pseudoaneurysm.

Procedure-related minor complications happened in two patients. One is mild biliary dilatation and the other is focal hepatic parenchymal ischemia which was managed conservatively.

\section{Discussion}

The accurate incidence of HAP is not clearly known but is approximately $0.02 \%$ in the general population and second most common visceral artery pseudoaneurysms [1] [3] [5]. Pseudoaneurysms are caused by blunt or penetrating injury, or iatrogenic injury within the liver and account for less than $30 \%$ but

Table 2. Angiographic evaluation with endovascular procedures and clinical outcomes.

\begin{tabular}{ccccccc}
\hline ProcedurePatient & Location & Size $(\mathrm{cm})$ & Procedures & Re-bleeding & Complication \\
\hline 1 & 1 & CHA & $3 \times 2$ & Coil packing & $(-)$ & $(-)$ \\
2 & 2 & PHA/RHA & $1.2 \times 1.1$ & Stent graft with coil packing & $(+)$ & $(-)$ \\
3 & & PHA & $0.6 \times 0.4$ & Coil packing & $(-)$ & $(-)$ \\
4 & 3 & PHA & $4.4 \times 3.6 \begin{array}{c}\text { Coil embolization } \\
\text { both afferent \& efferent segments } \\
\text { Coilpacking and embolization }\end{array}$ & $(-)$ & $(-)$ & $\begin{array}{c}\text { Mild biliary } \\
\text { dilatation }\end{array}$ \\
5 & 4 & LHA & $2.0 \times 1.5 \begin{array}{c}\text { Coth afferent \& efferent segments. } \\
\text { both }\end{array}$ & $\begin{array}{c}\text { Coil embolization } \\
\text { bild hepatic } \\
\text { ischemia }\end{array}$ \\
\hline
\end{tabular}

CHA: common hepatic artery; PHA: proper hepatic artery; RHA: right hepatic artery; LHA: left hepatic artery. 


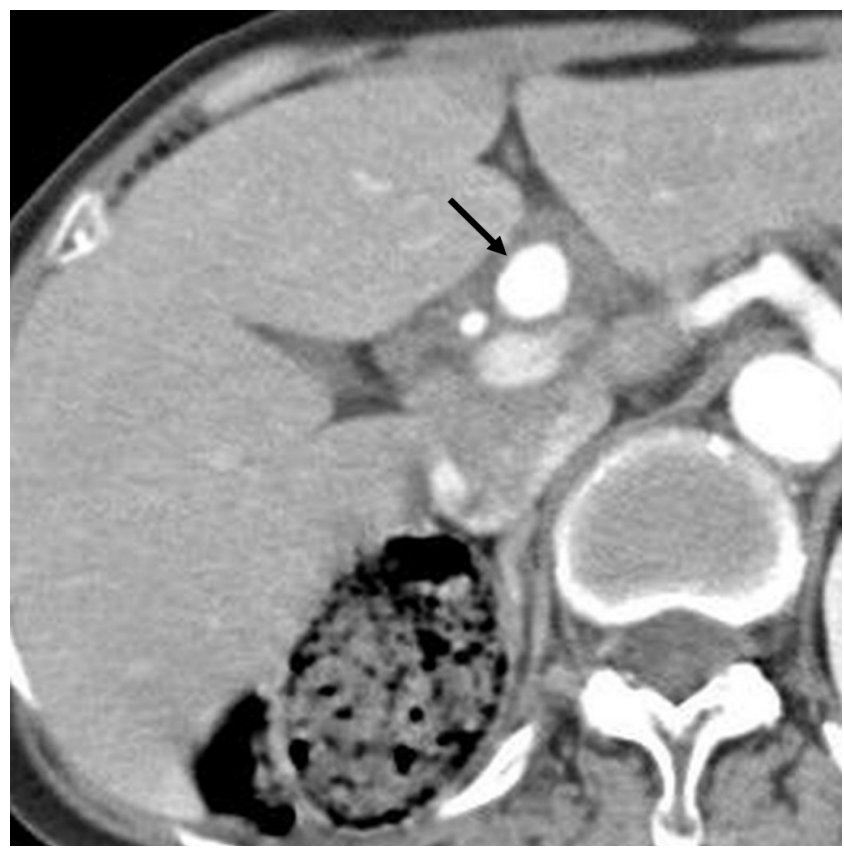

(a)

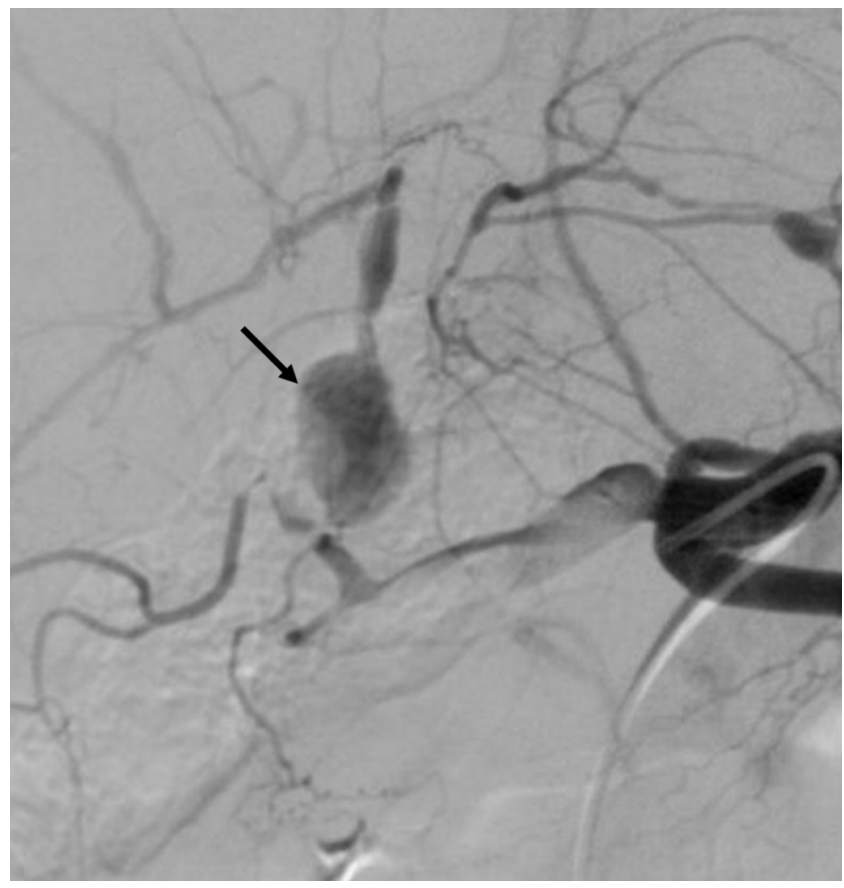

(c)

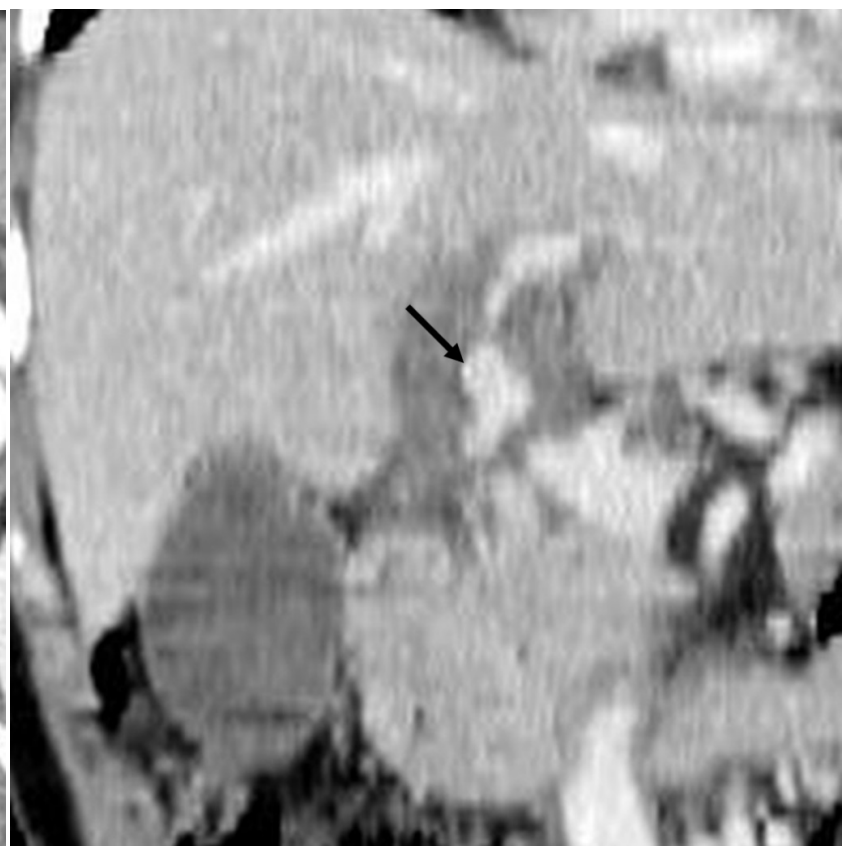

(b)

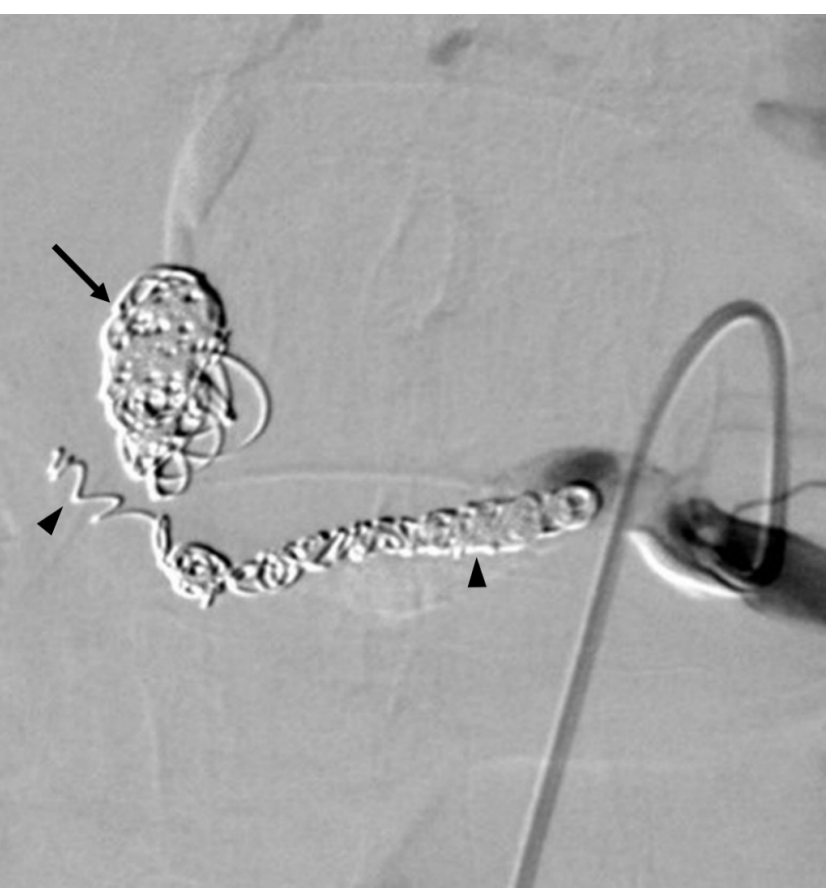

(d)

Figure 2. 62-year old female patient with epigastric pain. Abdominopelvic CT (a) (b) shows a $2.0 \times 1.5 \mathrm{~cm}$-sized pseudoaneurysmal sac (arrow) in proximal left hepatic artery. Angiography before procedure (c) reveals a pseudoaneurysm (arrow) from left hepatic artery. Coil packing (arrow) and additional embolization in both afferent segment and efferent segment (tornado coil, 10 $4 \mathrm{~mm}, \times 23$ ) (arrowheads) was performed on angiography (d). After discharge, mild bile ductal dilatation was noted without any laboratory abnormalities.

gradually increasing due to laparoscopic hepatobiliary surgery and invasive percutaneous procedures [2] [6] [9]. About $90 \%$ of HAPs are solitary and about $75 \%$ of HAPs are extrahepatic and common hepatic artery is involved about $63 \%$ 
[2] [9]. The common locations of HAPs are common hepatic artery (63\%), and right hepatic artery (28\%) [2]. Extrahepatic artery is more frequently affected by HAP after major pancreaticoduodenal surgery [10]. In our study, HAP in all two patients with history of Whipple's operation was limited at proper hepatic artery, whereas HAP in the other patients without pancreaticoduodenal operation was located at diverse segments of hepatic artery.

HAPs are often asymptomatic before rupture but the patient with ruptured HAP manifests hemobilia, epigastric or right upper quadrant pain and jaundice, so called Quincke's triad up to one third of cases [3] [9] [11]. Although rupture-related mortality rate in HAP is not negligible, the strong consensus regarding treatment indication and method is not yet established [2] [3]. The risk of rupture increases in the size greater than $2 \mathrm{~cm}$, which is indicated for treatment [1] [2] [3] [4] [5]. The other risk factors include multiple lesions [1] [9] [11]. The frequency of HAP rupture is less than $20 \%$ and mortality rate occurring with rupture ranges from $21 \%$ up to nearly $43 \%$ [1] [2] [3] [9].

CT angiography is the first step for optimal treatment planning [9]. Because there are numerous variations in hepatic arterial anatomy, determination of the type, number and localization of the pseudoaneurysm and its associated collaterals are evaluated by CT angiography [2] [9]. Treatment options for HAPs are largely classified into two categories: open surgical and minimally invasive interventional techniques [1] [2] [4] [5] [6] [7] [9] [11] [12]. The former one includes ligation and complete excision of HAPs with or without vascular reconstruction and the other one includes direct percutaneous thrombin or glue injection, endovascular methods of transarterial embolization or stent graft placement [1] [2] [4] [5] [6] [7] [9]. Direct percutaneous injection with thrombin or glue for aneurysmal sac is considered when neither transcatheter embolization nor surgical approach is difficult [5]. In recent five years, endovascular treatment has become the first choice of HAPs except ruptured HAPs [2] [5] [6] [9] [11]. The location and number are more important factors than the size and the gastroduodenal artery is pivotal in treatment algorithm [2] [6] [9]. Ligation or transarterial embolization of the hepatic artery distal to gastroduodenal artery can result in hepatic ischemia, abscesses, and cholecystitis if collaterals are insufficient [6] [9]. Therefore, CT angiography has a great role in evaluation of pancreaticoduodenal arcade, pericholedochal arteries, perigastric arteries, hypertrophic inferior phrenic arteries and arteries from the falciform or round ligaments [6] [9].

In our study, clinical success rate depended on the kinds of procedures despite $100 \%$ of technical success rate. Coil-packing of pseudoaneurysm only was less effective with $66 \%$ of clinical success rate than that procedure with additional embolization in both afferent and efferent segments with $100 \%$ of clinical success rate. This method might reduce risk of re-bleeding. We consider stenting as a useful modality for unique supplying artery for liver, which had spastic change, or underlying hepatic infarct but it should be handled more carefully because re-bleeding happened in the stent-replaced HAP. Simultaneous coil emboliza- 
tion and stent insertion for bleeding pseudoaneurysm, especially at branching segment, is not frequently performed, and which may be one of factors of recurred bleeding. Furthermore immediate following surgical procedure cannot be excluded for the reason of re-bleeding.

Two controllable complications were noted after coil embolization. One is mildly decreased hepatic parenchymal enhancement and the other is mild intrahepatic bile duct dilatation in corresponding arterial territories. These are related to hepatic arterial insufficiency distal to gastroduodenal artery. Only one case of coil embolization of distal branches to gastroduodenal artery did not result in arterial insufficiency, because enough collaterals were verified on hepatic arteriography.

Because of rarity of HAP, most published reports were case reports and few original articles with small numbers of patients [5] [9] [10]. In this study, we comprehensively reviewed diverse clinical presentation by various kinds of factors and proposal of minimally invasive endovascular management with consideration of clinical success and complication about HAP including our cases. Our study has several limitations such as the small number of patients and a retrospective study. However, follow-up examinations performed mean 13 months after procedures.

In conclusion, transcatheter arterial coil embolization for ruptured HAP is sufficiently effective and additional coil embolization in both afferent and efferent segment can improve clinical success rate. Further study and long-term follow-up is necessary.

\section{Conflict of Interest Disclosure}

The authors declared no conflicts of interest.

\section{References}

[1] Abbas, M.A., Fowl, R.J., Stone, W.M., Panneton, J.M., Oldenburg, W.A., Bower, T.C., Cherry, K.J. and Gloviczki, P. (2003) Hepatic Artery Aneurysm: Factors that predict Complications. Journal of Vascular Surgery, 38, 41-45. https://doi.org/10.1016/S0741-5214(03)00090-9

[2] Mohan, I.V. and Stephen, M.S. (2013) Peripheral Arterial Aneurysms: Open or Endovascular Surgery? Progress in Cardiovascular Diseases, 56, 36-56. https://doi.org/10.1016/j.pcad.2013.06.001

[3] Dawson, J. and Fitridge, R. (2013) Update on Aneurysm Disease: Current Insights and Controversies: Peripheral Aneurysms: When to Intervene-Is Rupture Really a Danger? Progress in Cardiovascular Diseases, 56, 26-35. https://doi.org/10.1016/j.pcad.2013.05.002

[4] Yu, Y.H., Sohn, J.H., Kim, T.Y., Jeong, J.Y., Han, D.S., Jeon, Y.C. and Kim, M.Y. (2012) Hepatic Artery Pseudoaneurysm Caused by Acute Idiopathic Pancreatitis. World Journal of Gastroenterology, 18, 2291-2294. https://doi.org/10.3748/wjg.v18.i18.2291

[5] Lu, P.H., Zhang, X.C., Wang, L.F., Chen, Z.L. and Shi, H.B. (2013) Stent Graft in the Treatment of Pseudoaneurysms of the Hepatic Arteries. Vascular and Endovascular 
Surgery, 47, 551-554. https://doi.org/10.1177/1538574413488460

[6] Nagaraja, R., Govindasamy, M., Varma, V., Yadav, A., Mehta, N., Kumaran, V., Gupta, A. and Nundy, S. (2013) Hepatic Artery Pseudoaneurysms: A Single-Center Experience. Annals of Vascular Surgery, 27, 743-749.

https://doi.org/10.1016/j.avsg.2012.08.018

[7] Fankhauser, G.T., Stone, W.M., Naidu, S.G., Oderich, G.S., Ricotta, J.J., Bjarnason, H., Money, S.R. and Mayo Vascular Research Center, C. (2011) The Minimally Invasive Management of Visceral Artery Aneurysms and Pseudoaneurysms. Journal of Vascular Surgery, 53, 966-970. https://doi.org/10.1016/j.jvs.2010.10.071

[8] Kim, S.K., Lee, J., Duncan, J.R., Picus, D.D., Darcy, M.D. and Sauk, S. (2014) Endovascular Treatment of Superior Mesenteric Artery Pseudoaneurysms Using Covered Stents in Six Patients. American Journal of Roentgenology, 203, 432-438. https://doi.org/10.2214/AJR.13.11644

[9] Polat, E., Ozogul, Y.B., Ercan, M., Karaman, K., Aksoy, E., Kucukay, F., Surmelioglu, A., Dalgic, T., Ulas, M., Bostanci, E.B. and Akoglu, M. (2012) Management of Hepatic Artery Aneurysms. Bratislava Medical Journal, 113, 676-679. https://doi.org/10.4149/BLL_2012_154

[10] Pedersoli, F., Isfort, P., Keil, S., Goerg, F., Zimmermann, M., Liebl, M., SchulzeHagen, M., Schmeding, M., Kuhl, C.K. and Bruners, P. (2016) Stentgraft Implantation for the Treatment of Postoperative Hepatic Artery Pseudoaneurysm. Cardiovascular and Interventional Radiology, 39, 575-581. https://doi.org/10.1007/s00270-015-1274-1

[11] Peter, G., Shaheer, R., Narayanan, P. and Vinayakumar, K.R. (2014) Hepatic Artery Aneurysm: A Rare Case of Obstructive Jaundice with Severe Hemobilia. Annals of Gastroenterology, 27, 288-289.

[12] Verzini, F., Biello, A., Marucchini, A., Parente, B., Parlani, G. and Cao, P. (2013) Total Endovascular Solution for Complex Visceral Aneurysms. Journal of Vascular Surgery, 58, 1412-1416. https://doi.org/10.1016/j.jvs.2013.05.045

\section{Abbreviations}

HAP: hepatic artery pseudoaneurysm.

CT: computed tomography. 
Submit or recommend next manuscript to SCIRP and we will provide best service for you:

Accepting pre-submission inquiries through Email, Facebook, LinkedIn, Twitter, etc. A wide selection of journals (inclusive of 9 subjects, more than 200 journals)

Providing 24-hour high-quality service

User-friendly online submission system

Fair and swift peer-review system

Efficient typesetting and proofreading procedure

Display of the result of downloads and visits, as well as the number of cited articles Maximum dissemination of your research work

Submit your manuscript at: http://papersubmission.scirp.org/

Or contact act@scirp.org 